\title{
PODE HAVER UMA ESTÉTICA FEMINISTA?
}

\author{
Claire Raymond
}

\begin{abstract}
RESUMo
"Pode haver uma estética feminista?" analisa a dificuldade em encontrar uma posição ontológica a partir da qual se escreva sobre as fotografias criadas por mulheres. Interroga-se acerca do desconforto de habitar, socialmente e na arte e na literatura, a posição do feminino corporizado e procura minar este desconforto através da análise estética. O ensaio argumenta que, apesar do desconforto social e intelectual de articular um espaço do feminino, na medida em que este espaço já é sempre codificado como um espaço de opressão, existe valor na interpretação da fotografia criada por mulheres através da lente da resistência feminista. $\mathrm{O}$ artigo reconhece que definir a palavra mulher é sempre arriscado, na medida em que este termo reflete variadas e contraditórias experiências corporizadas. E, no entanto, dentro deste risco reconhecido, emerge o único espaço de resistência possível à opressão, a oportunidade de criar um reordenamento do visível, para que a categoria da mulher oprimida, por muito irreal que seja, passe a ser refocalizada como soberana. Contudo, cada ato de refocagem da mulher deve ser culturalmente específico. Por isso, o ensaio termina com uma interpretação da série de imagens da fotógrafa etíope Aida Muluneh, intitulada Dinkinesh (ou "és bela"), recordando os restos de uma hominídea etíope que são há muito considerados como o mais antigo antepassado humano. Muluneh reivindica como etíope esta antepassada distante, vestindo-a com um extravagante vestido vermelho, usando a fotografia para refocalizar a entrada de Dinkinesh na história, concedendo a esta antepassada o poder de assombrar a modernidade.
\end{abstract}

\section{PaLAVRAS-Chave}

Feminismo; teoria estética; fotografia; Aida Muluneh; Walter Benjamin; Dinkinesh; assombro; mulheres fotógrafas

\begin{abstract}
"Can there be a feminist aesthetic?" analyzes the difficulty of finding an ontological position from which to write about photography created by women. It interrogates the discomfort of inhabiting, socially, and in art and literature, the position of the embodied feminine, and seeks through aesthetic analysis to mine this discomfort. The essay argues that despite the social and intellectual discomfort of articulating a space of the feminine, in that this space is always already coded as oppressed, there is a value in interpreting photography created by women through the lens of feminist resistance. The article concedes that defining the word woman is always a risk, in that the term reflects manifold and contradictory embodied experiences. And yet, within this avowed risk emerges the only space of possible resistance to oppression, the opportunity to create a rearrangement of the visible so that the category of the oppressed woman, however phantasmatic, is re-envisioned as sovereign. However, each act of re-envisioning woman must be culturally specific. Hence, the essay concludes with an interpretation of Ethiopian photographer Aida Muluneh's series of images Dinkinesh (or, "you are beautiful"), evoking the remains of an Ethiopian hominid that were long considered to be the oldest of human ancestors. Muluneh reclaims this distant ancestor as Ethiopian, dressing her in an extravagant red gown, using photography to re-envision Dinkinesh's fall into history, granting this ancestor the power to haunt modernity.
\end{abstract}

\section{KeYwords}

Feminism; aesthetic theory; photography; Aida Muluneh; Walter Benjamin; Dinkinesh; haunting; women photographers 
Em outubro de 2016 terminei um livro intitulado Women Photographers and Feminist Aesthetics e enviei o original ao editor. O processo da escrita deste livro, em particular o processo de interação com muitas das fotógrafas e o seu património, intensificaram a minha consciência de quão problemáticos e contestados são os lugares culturais do feminismo. É possível existir realmente uma estética feminista? Qual é a força política das imagens fotográficas para que algumas dessas imagens possam corretamente ser chamadas de feministas? Escolho como minha definição de feminista uma força de ação política - feminista não significa uma ideia respeitante aos sentimentos de uma pessoa acerca de si mesma, mas, em vez disso, para ter um significado, feminista deve sugerir uma força que leva ao compromisso político. A estética feminista aponta para um ato político sob a forma de imagem. O livro Women Photographers and Feminist Aesthetics é, por isso, uma obra de teoria e análise. Mas a luta prática com esta questão de uma estética feminista sofreu uma viragem bastante menos teórica quando cheguei aos capítulos que se referiam às artistas ainda vivas, ou às artistas com herdeiros vivos, e comecei a pedir autorizações de reprodução. Este ensaio é, portanto, uma espécie de Nachträglichkeit, um olhar em retrospetiva sobre a premissa do livro escrito, mas com uma nova perceção. Algumas das fotógrafas vivas analisadas no livro - certamente que nem todas elas - levantaram questões acerca das palavras mulher e feminista no título, refletindo o modo importante como a condição feminina enfaticamente não é um elo universal e as questões da colonização intelectual, e da colonização em geral, assombram o género.

Eu já conhecia, mesmo antes da publicação deste livro, as fissuras dentro dos espaços social e semiótico destes conceitos e termos, feminismo e mulher, as linhas de fratura que cruzam as estruturas nacionais, culturais, raciais e étnicas onde estão contidos estes significados. $E$, no entanto, através da interação com as artistas referidas no livro, aprendi sobre feminismo de maneiras que são inquietantemente teorizadas. As ligações, se é que existem, entre mulheres têm uma característica paradoxal de terra queimada e ao mesmo tempo inefável - viscerais, sentidas, irreais, repudiadas. De facto, a avaliar pelas várias respostas que me deram quando solicitei a autorização para usar as imagens neste livro, as ligações individuais das fotógrafas com estas palavras mulher, feminista, estão por vezes carregadas de ambivalência, vergonha e medo. Quem é que quer ser chamada mulher? Judith Butler, não.

Esta aventura de escrever sobre política e estética do feminismo ocorreu-me também devido ao meu lugar ambivalente na matriz de género. Tendo aceitado um lugar de professora provisória, após uma pausa de seis anos durante a qual fui mãe a tempo inteiro, tive de me esforçar por me manter à tona na academia. Há oito anos, numa universidade do sueste dos Estados Unidos, comecei a dar uma cadeira sobre mulheres fotógrafas, porque a então diretora do curso de Estudos sobre as Mulheres pensou que essa cadeira poderia ser popular (ela precisava de um número mais elevado de estudantes nas aulas do curso, a fim de manter o financiamento da universidade para esse curso). A diretora do curso de Estudos sobre as Mulheres pensou que, com o meu trabalho acerca da fotógrafa norte-americana Francesca Woodman, eu tinha uma base para poder ensinar. Mas, para mim, Francesca Woodman era interessante não por se tratar de uma 
mulher, mas por ser fotógrafa e criadora de imagens extraordinárias. Por isso, sem ter inicialmente um interesse profundo no tema, dei por mim a ministrar uma cadeira sobre mulheres fotógrafas que viria efetivamente a conquistar grande popularidade.

Semestre após semestre, as aulas estavam repletas de estudantes, na sua maioria cismulheres, e o seu entusiasmo por esta unidade curricular não tinha comparação com a resposta que eu obtinha noutras unidades curriculares, incluindo a de teoria feminista propriamente dita. A unidade curricular sobre mulheres fotógrafas ofereceu às jovens estudantes uma série de heroínas sob a figura de fotógrafas - figuras que, tal como Houdini, faziam algo de estranho e de mágico com a máquina fotográfica, afastavam delas próprias a contemplação masculina, criando mundos de imagem que questionavam e resistiam à opressão. Ao criarem objetos visuais (a fotografia é sempre um objeto, se bem que misteriosamente também reproduza a representação visual de outros objetos), estas fotógrafas moldaram uma esfera alternativa em que, apesar das difíceis circunstâncias reais vividas, a mulher fotógrafa criou uma visão de resistência, utilizou essa visão como resistência.

A fotógrafa Vivian Maier (1926-2009) personifica este golpe de magia. Filha de imigrantes franceses, Maier viveu na América em meados do século XX, trabalhando como ama, cuidando dos filhos dos outros durante toda a sua vida, ao mesmo tempo que tirava milhares de fotografias com a sua câmara de visor (Maloof \& Dyer, 2011). Em vida, nunca foi reconhecida como fotógrafa. As suas fotografias foram encontradas numa tenda-armazém após a sua morte e a maneira como começaram a ser conhecidas do público é uma história complicada: homens que compraram a tenda-armazém de Maier para pagar dívidas em atraso adquiriram também sem intenção as fotografias e depois puseram-nas em circulação (Maloof, 2014, pp. 19-36). Apesar de não ter tido papel absolutamente nenhum na divulgação das suas fotografias, as imagens de Maier insistem, obsessivamente, na visão desta mulher: o que ela vê, que ela vê. Nas suas fotografias, Vivian Maier não é criada de ninguém, embora o tenha sido toda a vida. Esta tenda (a tenda das fotografias-imagens e a tenda-armazém onde as fotografias-objetos estavam guardadas) onde a visão se torna imagem-objeto era fisicamente um lugar muito pequeno: as fotografias de Maier quase não foram impressas durante a sua vida, mas sim descobertas depois da sua morte em películas por revelar. Mas esta substância física tão leve, os rolos de película por revelar, expandiu-se de maneira a mostrar a visão singular de Maier sobre a América urbana de meados do século XX.

Certamente que muito mais pode ser dito acerca das condições de género e da precariedade da história de sucesso póstumo de Maier, mas o que pretendo evidenciar aqui é que os termos da sua subversão da fragilidade não foram, de um modo geral, o ponto de paragem que levou os estudantes a inscreverem-se na minha unidade curricular de "Mulheres Fotógrafas e Estética Feminista". A realidade da sua vida - Maier nunca deixou de ser ama de crianças até ficar tão velha que, na narrativa capitalista clássica, foi despedida e ficou na indigência - não foi o ponto de paragem para os estudantes. Em vez disso, o que os atraiu foi o efeito das subversões fotográficas de Maier: o facto de, apesar de ter passado a sua vida oprimida por circunstâncias de género e de classe, ter 
recusado essa sujeição na sua fotografia e de, na inquietante corporização da fotografia, esta recusa da sujeição constituir todo um mundo de imagem.

A imagem fotográfica é o lugar onde uma estética feminista ocorre e não ocorre: a vida real da fotógrafa não é necessariamente visível nem sequer significativa neste paradigma. Assim, liberta de me ocupar principalmente do sofrimento do que acontece nas vidas reais das mulheres fotógrafas, as minhas aulas de "Mulheres Fotógrafas e Estética Feminista" fervilhavam de uma energia invulgar: cada fotógrafa estudada tornava-se um modelo de alguém que imaginou um lugar onde a opressão ligada ao género foi superada na retórica da imagem fotográfica. As universitárias que frequentavam a unidade curricular enfrentavam as questões que as universitárias enfrentam: questões de imagem corporal, questões de sexo não consensuais, subtis proibições culturais de serem excessivamente bem-sucedidas nos estudos ou de terem êxito nos campos dominados pelos homens. Mas esta unidade curricular sobre fotografia nunca abordou diretamente nenhuma dessas questões. Em vez disso, dizia indiretamente, vejam, Lee Miller (19071977) sobreviveu à violação na infância e à tutela de Man Ray e ainda assim criou esta obra cheia de força (Burke, 2007). De facto, e para os objetivos desta unidade curricular, poder-se-ia dizer que Diane Arbus (1923-1971) e Francesca Woodman (1958-1981) sobreviveram ao seu próprio suicídio; a sua obra, e não as suas vidas, eram o tema da unidade curricular (Raymond, 2016; Arbus, 2003). E, contudo, a leveza mágica da transformação feminista através da imagem fotográfica que vivemos na sala de aula, no contexto de um livro que teve por base a unidade curricular, ganhou o peso do real. Transcrever em página os êxitos e as limitações das artistas mortais, uma tarefa muito mais difícil, tornou-se um ajuste de contas com a falta de à-vontade que as mulheres - incluindo eu própria - sentem quando se apresentam publicamente - isto é, perante homens - como mulheres. Na verdade, eu sabia, ao escrever o livro, que pelo facto de ter a palavra muIher no título nunca seria considerado tão importante, enquanto obra teórica, como um livro que não seja sobre mulheres. Todas as vezes que decidi escrever sobre mulheres, poetisas, fotógrafas, é com uma consciência crescente de que esta atividade me coloca numa espécie de gueto, isto é, num espaço enquanto académica em que se presume que eu nunca escrevi sobre nenhum assunto sério.

A dificuldade em impulsionar o feminismo como uma forma legítima de política está profundamente interligada com a dificuldade de escrever ou reivindicar a palavra mulher. A história destrutiva de ser designada de feminina, ou do seu cognato próximo feminista, roça de perto esta figura social chamada mulher (Solnit, 2017, pp. 17-69). E, no entanto, o feminismo e, por isso, a teoria feminista são entidades inteiramente políticas, derivando da polis e concretizando-a. O risco de reivindicar uma estética feminista tem, não apenas a ver com a força culturalmente carregada (e aviltada) da palavra muIher, mas também com o estatuto problemático do conceito de estética e da sua relação com a política. Na verdade, na medida em que a ontologia do género é provavelmente oca, isto é, determinada pelo aspeto exterior de uma pessoa e pela sua contextualidade, a estética e a política de género estão profundamente interligadas.

Refletindo sobre política e estética, recorro ao argumento persuasivo de Walter Benjamin acerca da ligação entre fascismo e estética. Nesta ligação está o cerne do risco de 
esteticizar o político; e também o argumento para a diferença entre esteticizar o político e politizar a estética. A estética da política, argumenta Benjamin (em 1931), está muito claramente expressa no fascismo (Benjamin, 1968a; Benjamin, 1972). O autor argumenta ele que o fascismo funciona privando as pessoas da oportunidade de uma melhoria material ou da oportunidade de participarem ativamente nas decisões políticas, a troco tácito da autorização sancionada para se exprimirem, ou seja, para exprimirem e darem crédito à sua cólera contra aqueles que elas determinam que não se assemelham a si mesmas. Benjamin prossegue estabelecendo uma ligação entre a autorização concedida pelo fascismo aos cidadãos para exprimirem o seu ódio por aqueles que consideram cair fora dos limites rígidos da cidadania supostamente correta e o papel da imagística no fascismo, da qual o exemplo mais flagrante seria o conceito de Hitler de um ideal ariano. Benjamin argumenta aqui que uma estética específica invade a política no fascismo, a imagem da superfície a cobrir o significado - o rosto que o fascismo cria esconde as suas ações sádicas (Hillach, Wikoff \& Zimmerman, 1979). Mas Benjamin não defende a conclusão de que a política esteticizada é sempre fascista. De facto, avança para a argumentação de que as imagens fotográficas também podem ser utilizadas para reforçar a resistência de esquerda ao fascismo.

A argumentação de Benjamin neste caso gira à volta da ideia de tempo e da sua representação na fotografia. Sugere que apenas o corte rápido e violento do momento da visão que a fotografia realiza capta com exatidão a condição atual, com as suas reviravoltas violentas e súbitas. A sua descrição, nas suas Theses, do Angelus Novus de Paul Klee (que Benjamin alcunha de "anjo da história") incide precisamente sobre a descrição fotográfica: ver a história num instantâneo repentino é a única maneira de a ver com exatidão (Benjamin, 1968b). Aqui, está implicitamente pressuposto que ver fotograficamente é a visão que nos pode ajudar a transcender a ideologia. Em debates anteriores sobre a fotografia, Benjamin também argumenta que a fotografia pode ser utilizada como instrumento para contrariar o fascismo devido à relação singular da fotografia com a duração: o instrumento para mostrar onde é que as coisas estão fraturadas e como é que os seus fragmentos podem voltar a encaixar uns nos outros. Ao encaixar umas nas outras fotografias diferentes (fotomontagem), a fotografia pode ter a sua força mais substancial de subversão ou de contracultura, defende Benjamin.

Jacques Rancière, em Aesthesis, argumenta que a forma estética é a única portadora verdadeira da mudança política, que não é o conteúdo político superficial de uma imagem que altera a cultura, mas sim, vez disso, aquilo que Rancière designa como aestheton, ou seja, a força estrutural-cultural da imagem. Aqui, Rancière afasta-se da noção de Clement Greenberg da estética como uma grelha, como pura forma, e afasta-se igualmente da noção de Benjamin de arte política planeada concertada (pensemos em Barbara Kruger, Martha Rossler). Em vez disso, ele argumenta (nas pegadas espectrais de Erwin Panofsky) que a forma transporta um conteúdo simbólico. Desta maneira, a fotografia política que reintroduz um conteúdo emprestado, criticando-o nessa revisão, repete também de alguma maneira silenciosa a inspiração original para esse mesmo conteúdo que deseja criticar. A forma simbólica que inverte e subverte a ideologia opressiva, nesse caso, tem de ser algo de novo, uma imagem ainda não vista. 
A aestheton - a força estrutural e cultural de uma imagem - é um efeito, mais do que uma intenção em sentido estrito. É possível que a intenção de uma fotógrafa possa produzir o efeito que ela quer, mas não é necessário. A teoria de Immanuel Kant da "ausência intencional de propósito" como a força definitiva do sublime vem-nos à memória neste ponto. Mas o argumento que Rancière apresenta acerca da qualidade emergente e imersiva da estética enquanto política tem tanto a ver com a política contemporânea como a teoria de Kant. A imagem ou transmite ou desarticula a força do mito social contido, tal como Diane Arbus sugere eloquentemente: "Uma fotografia é um segredo acerca de um segredo" (Lubow, 2016, p. 4). A imagem fotográfica diz o que diz sendo vista, não sendo mostrada. Trabalha sempre dentro do idioma do mito social e, no entanto, entra em conflito com, ou levanta objeções, aos termos do seu imaginário social contemporâneo através de alterações formais na imagem.

Se a estética feminista pode ser fotográfica, mais do que outros meios de comunicação, tal se deve à relação privilegiada e conturbada da fotografia com o tempo. Uma fotografia parece datada logo no ano da sua criação, e ainda mais à medida que o tempo avança para lá do plano congelado da fotografia. O tempo é a charneira da fotografia, expondo as suas qualidades formais ao embate e à brusquidão do facto tempo, à passagem do tempo num sentido cultural e material, e além disso o tempo é a porta da fotografia, a abertura através da qual o pensamento ou a convicção se revela pela sua ligação inquietante com o real material, corporizado. A ligação visceral e inquietante da fotografia com a passagem física do tempo torna-a vulnerável e politicamente poderosa: pertence sempre ao momento e pode também (embora raramente) ultrapassar o momento mantendo-o parado num ato de visão translativa, aquele que atravessa, que traduz o material e o social em imagem e que modifica o espectador.

A duração fotográfica e a fragmentação da opressão significam: uma fotografia pode mostrar ou recusar a maneira de ver que se tornou uma forma de domínio. A fotografia pode ser um objeto de combate, tal como existe materialmente, movendo-se visualmente contra o hábito material como condição de entendimento. A duração da fotografia é ao mesmo tempo instantânea e perene; o seu próprio espaço hiper-real, comentando, comemorando e moldando o mundo material vivido, iterativamente ligada a ele. A fotografia é uma espécie de circunflexo, que inflete os modos de observar e, como tal, é um instrumento óbvio para a política.

\section{O ANJO DA HISTÓRIA}

Tal como foi referido no início deste ensaio, a utilização feita por Benjamin do termo "anjo da história" descreve com extraordinária eloquência a maneira como a fotografia compõe, e reflete, as fraturas ou a existência da vida atual (Benjamin, 1968b). Neste sentido, este ensaio reflete implicitamente a força política da fotografia. A teoria de Benjamin do inconsciente óptico sustenta o seu argumento de que a fotografia é o meio mais capaz de transmitir a moderna realidade do choque; uma fotografia pode mostrar-nos o que nela existe e que nós habitualmente suprimimos na edição ou de que 
desviamos o olhar. Esta completude, dentro do mundo restrito da imagem fotográfica, torna a fotografia inquietante na revelação que ela faz de aspetos estratificados da história catastrófica. Ao contrário de outras formas de arte, a fotografia não é recordada nem filtrada, mas suplanta a função da memória e filtragem. Mesmo quando a fotografia funciona como um análogo da memória, ela substitui o discurso interior da memória e filtragem e, neste desvirtuamento do tempo, funciona como um déjà- vu, ou um trauma.

Sobre o conceito da história de Benjamin, em que ele descreve o Angelus Novus de Paul Klee como um "anjo da história" debatem-se com o fotográfico (Benjamin, 1968b, p. 257). Porque, aqui, Benjamin argumenta que aquilo que nós apreendemos com uma cadeia de acontecimentos, a história, é realmente um acontecimento (traumático, uma catástrofe) (Benjamin, 1968b, p. 257). Esta metáfora está tão profundamente imersa no visual que conjura o instantâneo fotográfico, aquele instante em que uma imagem se imobiliza como imagem. A qualidade de trauma que é bastante óbvia nas suas considerações Sobre o conceito da história aponta para a teoria de Benjamin sobre a fotografia como um aparelho visual traumático ou uma técnica em que o trauma é elemento constituinte.

O trauma da fotografia é a brusquidão e o carácter absoluto com que regista a imagem do que aconteceu. Não só é esta a maneira de a imagem ser traumática - isto é, temporariamente brusca - como reflete também o trauma da modernidade, a maneira como as coisas acontecem subitamente sem estarmos preparados para elas (tais como acidentes de viação, ou, na referência de Benjamin, a ascensão do nazismo). Mas a fotografia é também uma imagem que pode conter informação acerca do passado-presente-futuro numa só forma. A fotografia é ao mesmo tempo um meio que impõe um olhar traumático - um olhar rápido, súbito, fraturado - e que é também capaz de registar traumas estratificados. A fotografia enquanto meio de comunicação do trauma é o olhar de Benjamin acerca da relação elíptica da fotografia com a aura. A imagem fotográfica despoja a aura de tudo o que não é fotográfico, ficando neste processo ela própria despojada de aura (completude, verdadeiro significado ontológico). E, no entanto, a fotografia também pode ser dotada de aura, na qual ela aparece - nas elípticas teses Sobre o conceito de história de Benjamin - como a única maneira em que o trauma da história pode ser visto: fotograficamente, num instantâneo. A reivindicação de Benjamin de que tudo o que "foi esmagado" só pode ser refeito se virarmos e num instante virmos as camadas da história, não em sequência mas todas ao mesmo tempo, sugere não apenas um modo fotográfico de ver, mas um modo fotográfico de ver em colagem (Benjamin, 1968b, p. 257).

A força erosiva das fotografias - que retiram do contexto todas as pessoas, objetos e acontecimentos que representam - é também o que confere à fotografia a sua força estética traumática. A máquina fotográfica enquanto anjo da história pode ser virada para ver o que está esmagado, mas não pode em si mesma salvar nada do que vê, compelida como está pelos usos do progresso. A capacidade das fotografias de serem arrancadas do contexto reflete e representa a estrutura social do mundo moderno que é continuamente imprevisível, violenta e aleatória. A fotografia feminista faz uso desta capacidade 
traumática inerente à fotografia para expor, elíptica e liricamente, simbólica e formalmente, o trauma da opressão sexista nos seus diversos contextos históricos específicos.

Se aceitarmos, com Benjamin, que a fotografia é quase sempre política (mesmo e de facto especialmente as imagens que consideramos como privadas e pessoais promovem uma política), de que maneiras pode a fotografia feminista diferenciar-se da utilização fascista da imagem, imagens que são criadas para conter e controlar a imaginação da polis? Por outras palavras, um dos pontos que Benjamin mais aprofunda, e isso é o mais perturbador, acerca da fotografia e da política é a medida em que a fotografia é um instrumento "natural" do fascismo, e não devemos ignorar esta capacidade da fotografia de fazer circular imagens de opressão quando procuramos elucidar de que maneira a fotografia pode também combater a opressão. Se bem que as primeiras críticas de uma estética feminista - Barbara Freeman e Rita Felski - tenham levantado objeções à ideia de que podia existir uma visão feminista uniforme (baseando os seus pressupostos na convicção de que uma tal estética afirmaria uma falsa ideologia de unidade entre as mulheres), a minha preocupação reside menos no espetro de uma feminilidade unária e mais na força espetral da fotografia; na sua vulnerabilidade a ser usada como propaganda (Freeman, 1997). Como pode uma estética feminista, na fotografia, ser diferente de uma estética fascista, não apenas nas opiniões, mas formalmente, estruturalmente? Pode a fotografia ser radical ou repete sempre os próprios termos culturais que permitem a sua leitura? Qual é então a relação entre género e tempo, entre movimento feminista e tempo?

Para esta pergunta, recorro a uma fotógrafa cujo trabalho, à semelhança da sua história pessoal, alterna entre as estruturas capitalistas dominantes do Ocidente e o cruzamento poderoso e precário da antiga e da nova cultura na África Subsaariana contemporânea. A fotógrafa Aida Muluneh, nascida na Etiópia, viveu durante décadas noutros países - lémen, Inglaterra, Chipre, Canadá, EUA - e depois trabalhou como fotojornalista para o Washington Post, até que decidiu regressar à sua Adis Abeba. Adotou o apelido do seu avô materno, Muluneh, para representar a sua ligação à Etiópia através da mãe (que a criou sozinha). Após o regresso à Etiópia, voltou o seu olhar de fotojornalista para o país pelo qual sentia uma imensa nostalgia e onde, como refere, "a nostalgia é o nosso desporto nacional". Past/Forward (2009), o trabalho resultante do reencontro inicial de Muluneh com a Etiópia, é fotografia documental com uma intensidade lírica, um trabaIho de busca e deslumbrante, mas é a obra de Muluneh a partir de 2010 que eu sugerirei que contém uma óbvia estética feminista'.

Nestes trabalhos - 99 Series, The Wolf You Feed e The World is 9 - Muluneh cria uma fotografia avant-garde que, enquanto obras fotográficas, incorpora pintura, cenários e guarda-roupa, para formar imagens altamente simbólicas das mulheres africanas em ambientes que são referências à história da Etiópia, mas fá-lo obliquamente, simbolicamente e no próprio vocabulário imagístico de Muluneh. Estas obras mais recentes centram-se muitas vezes exclusivamente numa mulher, num modelo feminino.

'Aida Muluneh Past/Forward: Photography in Ethiopia, Colby College Art Department Lecture, Waterville, Maine, 23 abril 2015 . 
Estes modelos são mulheres escolhidas por Muluneh porque, segundo diz, tal como ela, também transportam visualmente a simbologia da Etiópia no seu corpo: isto é, outras pessoas que as vejam interpretam-nas como sendo mulheres africanas. As suas fotografias, portanto, recorrem à história das representações fotográficas de mulheres africanas como rebaixadas, famintas e desumanizadas e subverte esta imagística, não apresentando contraimagens realistas, mas criando em vez disso uma paisagem visual simbólica que incentiva o espectador a interpretar as mulheres africanas retratadas nos termos definidos pela fotografia de Muluneh, em vez dos termos masculinistas opressivos ocidentais.

As fotografias que compõem a série de 2014 The Wolf You Feed centram-se primordialmente numa jovem africana com o corpo coberto por uma tinta espessa. Na tinta densamente aplicada, Muluneh não permite inferir a raça: a pele da mulher está tão espessamente coberta de tinta que nada de natural pode ser deduzido acerca do aspeto da pele. Este uso emblemático da tinta é o sinal de Muluneh de que as suas fotografias não devem ser interpretadas como imagens acerca da diferença racial, mas em vez disso opõem-se à construção da raça e à ideologia colonialista e, na sua objeção, combatem esta história. Tal como a fotógrafa faz notar, "as fotografias podem criar ou distorcer a realidade". Um grande plano do rosto da jovem modelo coloca-nos de olhos nos olhos com ela (Figura 1). Muluneh posiciona a imagem de modo a ficarmos face a face com a mulher (Muluneh, 2009).

Tal como argumenta o filósofo Emmanuel Levinas, "estar face a face" é a atitude ética em que assumimos a posição da outra pessoa que está à nossa frente: olhando de olhos nos olhos somos arrastados para um contrato moral com a pessoa que está à nossa frente (Hand, 2011). A modelo de Muluneh olha para nós com a pele pintada de azul e dividida a meio por pontos negros (uma alusão à pintura xhosa dos adolescentes durante a transição para a idade adulta) (Jayawardane, 2016)². As mãos pintadas de preto e de vermelho escuro, também divididas a meio com pontos, seguram o rosto da modelo: está presa na história, mas é lúcida. Estas fotografias desnaturalizadas eliminam os conceitos de veracidade fotográfica, aquilo a que Baudrillard chamou a capacidade diabólica de substituir o real pelo falso (Baudrillard, 1994). Em vez disso, as fotografias de Muluneh acentuam a sua própria encenação elaborada, invertendo as diabólicas substituições das imagens fotojornalísticas do sofrimento africano, imagens (como as de Anthony Suau, Sebastião Salgado e James Nachtwey) que apresentam a identidade africana como inteiramente corpórea e brutalizada. Em contraste com as imagens invasivas do fotojornalismo ocidental, Muluneh abre um espaço eidético e onírico de possibilidade simbólica.

A sua série de fotografias reconstituindo os passos e a queda de Lucy (referindo-se aos restos ósseos de uma hominídea primitiva encontrados na Etiópia e que os antropólogos acreditam há muito ser o esqueleto mais antigo de um ser humano) inverte o olhar científico masculino do Ocidente e, em vez disso, afirmam uma mulher brilhantemente poderosa que, na imagística de Muluneh, é mítica, em pé ou caída, no seu próprio mundo, não para ser usada por outros (Figuras 2 e 3) (Kimbel \& Delezene, 2009). Porquê a

\footnotetext{
${ }^{2}$ Aida Muluneh, Comunicação pessoal à autora, agosto 2016.
} 
fotografia para estas paisagens de imagem altamente simbólica que não passam de instantâneos? Porque a fotografia, com o seu conceito do natural e do realista, proporciona precisamente a tensão de que Muluneh necessita para inverter as maneiras opressivas de ver. O conceito realista que é intrínseco à fotografia, Muluneh retira dele, subverte e dá-lhe largas através de imagens altamente orquestradas que resistem a tornar-se hiper-reais, ou seja, resistem a trocar o real que pode ser visto pela ideologia que é mostrada. As suas fotografias opõem-se à ideologia e recusam apresentar a mulher africana como terreno para a imposição de símbolos alheios. Em vez disso, Muluneh reinveste esta figura com potência que ao mesmo tempo radica na história africana e é enigmaticamente pessoal, fundindo os padrões da pintura de rosto xhosa com enquadramentos de pinturas de ícones ortodoxos etíopes (Jayawardane, 2016) 3 .

Refutando um estereótipo arqueológico e antropológico - o de Lucy, a mulher etíope como "mãe" de todos os seres humanos - Muluneh apresenta Lucy como uma presença enigmática e aterradora, pairando sobre tudo o que se torna humano, supervisionado o que vê em vez de se tornar objeto de um olhar científico. Tal como Michel Foucault evidencia em O Nascimento da Clínica, o olhar científico é um olhar de domínio, dominando através do escrutínio e, longe de ser objetivo, a sua compulsão pelo poder e pela dominação está tão totalmente mascarada que perverte a ideia de objetividade (Foucault, 1994). Na sua fotografia, Muluneh reivindica Dinkinesh, ou Lucy, suplantando o lugar do olhar científico.

A força inquietante e dolorosa da fotografia de Muluneh desenrolou-se quando escrevi o capítulo sobre a sua obra. Tive de reencarar o problema feminista da inadmissibilidade do conhecimento de ser mulher: porque este conhecimento não tem um cerne - uma estética feminista é sempre uma resposta visual a um conjunto muito específico de circunstâncias culturais e da história. Sendo mulher branca, americana, posso falar sobre e abordar as questões que as mulheres africanas enfrentam, mas não posso falar a partir do lugar dessas questões. Em vez disso, as imagens criadas por Muluneh falam a partir desse lugar e a tarefa da minha escrita foi, e é, encontrar a nova limpidez da sua visão. Uma estética feminista, portanto, é tipificada por uma força que não pode ser prevista. A sua distância da representação fascista enquanto política reside aqui: o desejo do fascista é sempre susceptível de ser conhecido antecipadamente. Mas o desejo da artista mulher que pretende que vejamos com um novo olhar, que reordenemos o visível (tal como Rancière argumenta em $O$ espectador emancipado), apenas é suscetível de ser conhecido depois de a obra ser entregue a um público, isto é, a pessoas que sejam ao mesmo tempo conhecedoras e desconhecedoras do lugar de origem da artista, no seu sentido mais lato (Rancière, 2009).

$\mathrm{Na}$ interação com o público - o ato da perceção - ocorre o acontecimento estético. Com isto, não invoco necessariamente a teoria de Barthes da morte do autor, potencializando o texto legível para a fotografia, o acontecimento visto; em vez disso, pretendo dizer que a força da estética que contém em si e é motivada por traços da história e da cultura (sem os quais não tem nenhum significado) é feminista na resposta e na criação

\footnotetext{
${ }^{3}$ Comentários acerca das pinturas de rosto xhosas, Aida Muluneh, comunicação pessoal à autora, agosto 2016.
} 
de vocabulários de imagens culturalmente específicas que revelam maneiras opressivas de ver e oferecem uma espécie de catarse retardada, livrando-se da velha e substituindo-a por uma intensidade do violento (Barthes, 1977). As volumosas roupas vermelhas vestido e capa - de Dinkinesh, nas fotografias de Muluneh de 2016, sugerindo o sangue com todos os seus significados amplos e culturalmente indeterminados, fazem recuar ao olhar clínico eurocêntrico, honrando uma mulher africana que ficou na história, recuperando-a e rebatizando-a em amárico: o seu nome, que significa és bela.

A ideia de Barthes do punctum - a dolorosa força estética das fotografias individuais - foi escrita, sugiro eu, em parte como resposta e refutação à Família de Man, isto é, como uma rejeição à ideologia através da qual a fotografia foi lançada como uma "linguagem universal" (Barthes, 1972). O punctum de Barthes declara que nunca é assim. $O$ punctum - a flecha - de uma fotografia com estética feminista é este presente, doloroso e aprazível, de desfazer o que outrora nos mostraram opressivamente, para podermos agora ver com um novo olhar. A linguagem das fotografias de Muluneh é específica, do seu país, das suas origens, e a partir desta especificidade aborda a apropriação ocidental de Dinkinesh e a reivindicação etíope desta última - não apenas dos seus ossos, mas da sua história, enigmática, e no lugar correspondente.

Aida Muluneh é aqui discutida como exemplo de uma estética feminista na fotografia. O seu trabalho assume um discurso histórico - a história da Etiópia tanto em si mesma como nas suas interações com o Ocidente - e dá-lhe a sua forma profundamente simbólica. As suas imagens veem através da perspetiva quase apagada desta mulher, Dinkinesh. A possibilidade da força feminista das fotografias é sempre problemática. Necessita que a própria fotógrafa seja capaz de ver a partir de uma perspetiva feminista, tarefa que de modo algum é coerente ou alinhada com o simples facto de ser mulher. Pelo contrário, o ponto crucial do ativismo feminista na fotografia reside na fotógrafa interpretar ou não o mundo à sua volta como um mundo que necessita urgentemente de mudança política. Dito isto, não são as convicções confessas da fotógrafa que moldam a imagem. Em vez disso, é a compreensão do mundo político que ela habita e que ocorre a um nível inferior ao limiar da declaração pública que gera a força estética da intervenção feminista na imagem fotográfica. Por outras palavras, a própria fotógrafa pode ou não confessar publicamente um ativismo político a favor da igualdade de género. $O$ que molda uma estética feminista é o risco da forma, contorno e símbolo que ocorre na própria imagem. Uma imagem fotográfica é sempre política: emerge de um espaço político, por mais privado que possa parecer, e afeta a política do mundo em que é vista. $\mathrm{Na}$ sua maioria, as fotografias não pretendem ser conscientemente entidades políticas, mas possivelmente é sempre esse o seu destino. A circulação de fotografias molda-nos, formando o imaginário cultural que é o mundo humano. A fotografia feminista, como a de Aida Muluneh que analisámos atrás, responde a esta realidade do mundo de imagem. Articula novas formas que entram no domínio social e altera a possibilidade de significado que associa ao género e ao ser.

Traduzido por Martin Dale (Formigueiro Lda) 


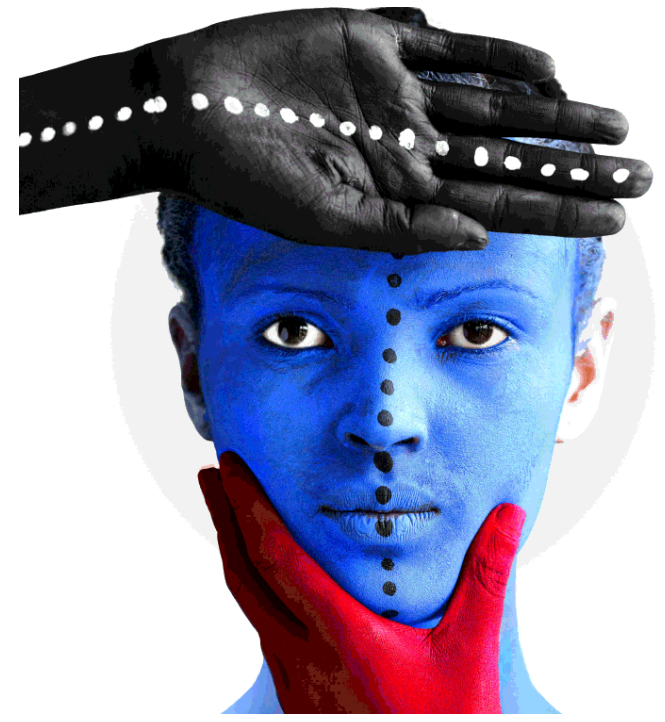

Figura 1: Aida Muluneh, Conquest, Série The Wolf you feed, 2014 Fonte: https://www.aidamuluneh.com/work/\#/the-wolf-you-feed-1/

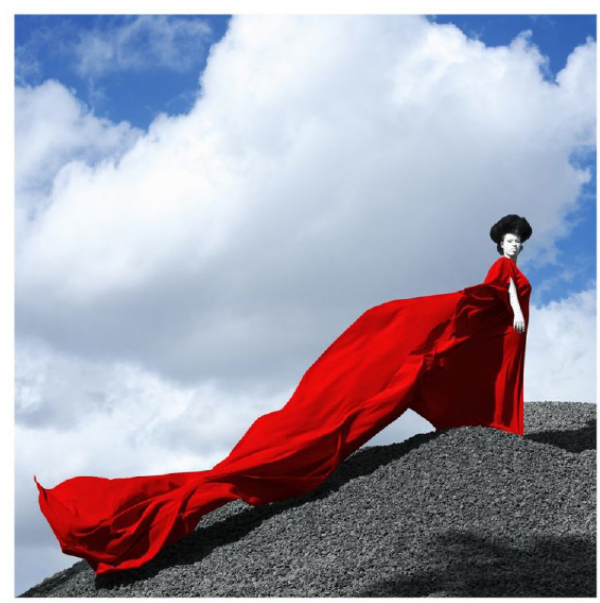

Figura 2: Aida Muluneh, Dinkinesh Part Three, Série The world is 9, 2016 Fonte: https://www.aidamuluneh.com/work/\#/the-world-is-9-1/

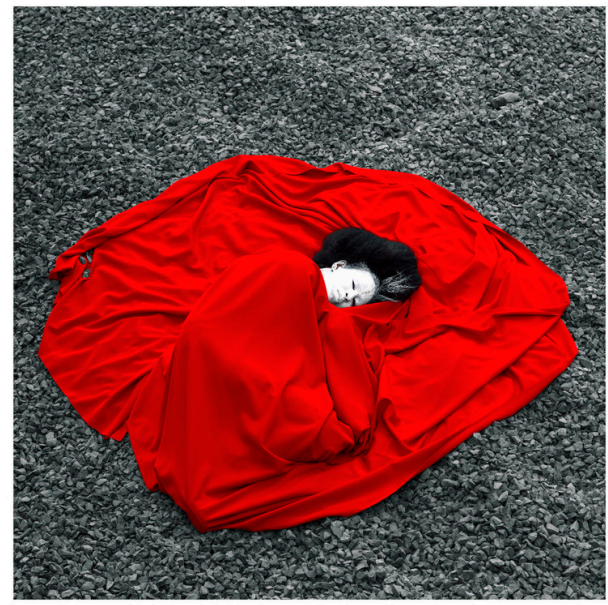

Figura 3: Aida Muluneh, Dinkinesh Part One, Série The world is 9, 2016 Fonte: https://www.aidamuluneh.com/work/\#/the-world-is-9-1/ 


\section{REFERÊNCIAS BIBLIOGRÁFICAS}

Arbus, D. (2003). Revelations. Nova lorque: Random House.

Baudrillard, J. (1994). Simulacra and Simulation. Michigan: University of Michigan Press.

Barthes, R. (1972). Mythologies. Nova lorque: Farrar, Straus \& Giroux.

Barthes, R. (1977). The Death of the Author. In Image, Music, Text (pp. 142-147). Nova lorque: Hill and Wang.

Benjamin, W. (1968a). The Work of Art in the Age of Mechanical Reproduction. In H. Arendt (Ed.), Illuminations (pp. 217-252). Nova lorque: Harcourt, Brace, Javonich.

Benjamin, W. (1968b). Theses on the Philosophy of History. In H. Arendt (Ed.), Illuminations (pp. 253-264). Nova lorque: Harcourt, Brace, Javonich.

Benjamin, W. (1972). A Short History of Photography. Screen, 13(1), 5-26.

Burke, C. (2007). Lee Miller: A Life. Chicago: University of Chicago Press.

Foucault, M. (1994). The Birth of the Clinic. Nova lorque: Penguin.

Freeman, B. C. (1997). The Feminine Sublime. Gender and Excess in Women's Fiction. California: University of California Press.

Hand, S. (2011). Facing the Other: the Ethics of Emmanuel Levinas. Londres: Routledge.

Hillach, A., Wikoff, J. \& Zimmerman, U. (1979). Walter Benjamin's 'Theories of German Fascism'. New German Critique, 17 [Special Walter Benjamin Issue], 99-119.

Jayawardane, M. N. (2016). Between Nostalgia and Future Dreaming, Transition 120, 116-131.

Kimbel, W. \& Delezene, L. (2009). 'Lucy' Redux: a Review of Research on Australopithecus afarensis. Yearbook of Physical Anthropology, 52, 2-48.

Lubow, A. (2016). Diane Arbus: Portrait of a Photographer. Nova lorque: Ecco.

Maloof, J. \& Dyer, G. (2011). Vivian Maier: Street Photographer. Nova lorque: Powerhouse Books.

Maloof, J. (2014). Vivian Maier: A Photographer Found. Nova lorque: Harper.

Muluneh, A. (2009, 22 de julho). Ethiopia: Past/Forward Aida Muluneh Book [Post in a blog]. Retirado de http://muluneh.blogspot.com/2009/07/ethiopia-pastforward-aida-muluneh-book.html.

Rancière, J. (2009). The Emancipated Spectator. Londres: Verso.

Rancière, J. (2013). Aisthesis. Scenes from the Aesthetic Regime of Art. Londres: Verso.

Raymond, C. (2016). Francesca Woodman's Dark Gaze: the Diazotypes and Other Late Work. Nova lorque: Routledge.

Solnit, R. (2017). The Mother of All Questions. Chicago: Haymarket. 


\section{Nota BiográficA}

Claire Raymond é professora da unidade curricular de História de Arte e do Departamento de Sociologia da Universidade da Virgínia. Os seus livros Women Photographers and Feminist Aesthetics, Francesca Woodman and the Kantian Sublime, Witnessing Sadism in Texts of the American South, e Posthumous Voice in Women's Writing from Mary Shelley to Sylvia Plath exploram temas relacionados com o género, fotografia e teoria da estética. É doutorada em Literatura Inglesa pela Graduate School and University Center, City University of New York.

E-mail: scp2u@virginia.edu

University of Virginia, Charlottesville, VA 22904, 434 293-6653, United States of America

* Submetido: 28-07-2016

* Aceite: 30-09-2017 